Michael W. Stadler

\title{
Thinking, Experiencing and Rethinking Mereological Interdependence
}

\section{Introduction}

The contemporary German philosopher M. Gabriel introduces his most recent book Der Sinn des Denkens with the statement that "thinking is perhaps the central concept of philosophy. Since Plato and Aristotle, philosophy understands itself as a science that thinks about thinking" (Gabriel, 2018, p. 11; own translation). The (re) thinking of thinking for the sake of philosophizing becomes even more urgent in cases when thinking alone is insufficient to fully understand a certain notion. When thinking about thinking has to go beyond pure thinking in order to understand, philosophy is well advised to open itself and turn into an interdisciplinary undertaking. A case in point is the idea of interdependence in the context of part-whole relations. This is the idea that the existence of a whole depends on the existence of (at least one of) its parts and (not or) vice versa. A better understanding of what can be labeled 'mereological interdependence' (MI) would be beneficial for issues of partwhole interactions related to, for example, topics as diverse as fractals in mathematics and physics, the notion of 'contraction' in Cusanus' negative theology, the structure of conceptual metonymy in cognitive linguistics, Goethe's metamorphosis of plants and the mental act of restructuration in problem solving.

Since it is difficult for traditional philosophical (or more precisely, ontological) models to think MI, I suggest to rethink it by following an interdisciplinary approach. In the first section, the formal part-whole ontology of Edmund Husserl's third Logical Investigation serves to demonstrate the difficulty of mI's thinkability. The second section goes beyond the Husserlian model by considering empirical findings from Baingio Pinna's current research on the perception of meaningful gestalts. In general, philosophical interpretations of gestalt-theoretical findings are to the point. This is not only because of the historical interconnection between the two fields (cf. Ash, 1985, p. 296), due to which Gestalt theory "had been able to combine philosophical sophistication with ingenious experimental strategies" (Harrington 1996, p. 103). In addition, Gestalt-theoretical research constantly operates on the borderline with philosophy by touching upon notions such as (supra-)summativity (cf. Rausch, 1967) and emergence (cf. Pomerantz \& Cragin,

O Open Access. ( 2019 Michael W. Stadler, published by Sciendo. (c) BY-NC-ND This work is licensed under the Creative Commons Attribution NonCommercial-NoDerivatives 4.0 License. 
2015), reality and existence (cf. Metzger 2001), ethics (cf. Næss \& Haukeland, 2002), esthetic values (cf. Arnheim, 1974), axiology (cf. Köhler, 1939), or phenomenology (cf. Albertazzi, 2015). Despite the relevance of philosophical topics and methods for Gestaltist research, for which the here discussed ontological determination of part-whole relations and their hierarchies is another example, the conclusion of B. Smith's 1988 essay 'On Gestalt Theory' still reverberates:

\begin{abstract}
"[...] a truly adequate mastering of the philosophical difficulties which surround this idea [of a Gestalt] has never really taken place. [...] Such philosophical, and above all ontological, clarification is needed, for, without an awareness of the nature and interrelations of the objects with which it deals, an empirical science is in a certain sense performing experiences in the dark." (Smith 1988, p. 69)
\end{abstract}

Therefore, the third section suggests a constructive, experience-based answer to rethink Mi for philosophy's sake. The present paper generally aims to stimulate reflections within Gestalt theory itself on the question of which kinds of partwhole relations we are presupposing when a certain understanding of a 'Gestalt' is used. A philosophically inspired reflection on its own philosophical presuppositions does justice to the holistic spirit of early Gestalt theory and thus can supplement more recent, laboratory studies in this domain.

\title{
I. Thinking Mereological Interdependence: E. Husserl
}

To demonstrate the hypothesis of the difficulty to think MI in a purely logical manner, it is beneficial to delineate the model of part-whole relations that E. Husserl provides in his third Logical Investigation. Apart from being an essential key to Husserl's later works (cf. Ströker 2009, p. xlvi), this text is an influential philosophical document in its own right, perhaps "the single most important contribution to realist (Aristotelian) ontology in the modern period" (Smith \& Mulligan, 1982, p. 37). It is not surprising that philosophically inspired Gestalt psychologists like M. Wertheimer were well aware of it (cf. Smith 1994). Furthermore, like only few other ontological models, we can classify the one of Husserl as an unfinished 'open source code,' because

"the investigation remains only a sketch of what a fully developed formal theory would look like, and like all philosophical sketches, presents problems of interpretation, lacunae, and vagueness, as well as being highly suggestive of possible fruitful developments." (Simons, 1982, p. 113f.)

In the case of MI, the Husserlian model is indeed suggestive of such developments, because it reaches its limits exactly when it comes to the thinkability of this notion. Husserl argues that what is thinkable without any interference of empirical perception or any other kind of experience are analytic laws and universal categories. 
Like Platonic ideas, our mind can grasp them directly, because they are "free from all explicit or implicit assertions of individual existence; they include none but formal concepts, and if we go back to such as are primitive, they contain only formal categories" (Husserl, 2001, p. 20). The domain Husserl described here is the one covered by a 'formal ontology' that concerns "what all objects and object-regions have in common" (Smith \& Smith, 1995, p. 29). As such, it stands opposed to a 'material ontology' that relates to the domain of what is a perceptible and contingent instantiation of its formal genus. In other words, material ontology relates to the ontic nature and existence of particular objects that can appear in reality, not to the universal principles and properties underlying the reality of appearances. We have to keep in mind for the following argumentation that the true propositions a formal ontology makes of the latter are supposed to provide the truth conditions of the former. What is impossible to think cannot or at least should not be actual to experience, because the contents of experience are only a particular instantiation of their general ideas.

To illustrate this, we can now turn to the two major categories Husserl's ontological model is all about: the nature of and relation between part(s) and whole(s). Both our formal thinking of reality and the concrete reality in its givenness are domains in which (relations between) parts and wholes are pervasive. In a formal sense, we can think of axioms such as the ones of transitivity ('if $b$ is part of a and $c$ is part of $b$, then $c$ is part of $a$ '), asymmetry ('if $a$ is part of $b$, then $b$ cannot be part of a') and irreflexivity ('a cannot be part of itself') without recurrence to concrete experiences. The phenomenal realm instantiates such mereological laws for example in the perception of an apple. If the apple core is part of the whole apple and the seeds are part of the core, then the seeds are part of the whole apple (transitivity); if the core is part of the whole apple, then the whole apple cannot be part of the core (asymmetry); an apple cannot be part of itself (irreflexivity). It is laws of part-whole relations like these that have been fundamental for contemporary extensional mereology (cf. Varzi, 2016).

Only in considering these laws and their supposed universality in the light of another distinction, however, we can arrive at the idea of MI in Husserl's model. This is the distinction between independent and dependent parts. It dates back to the empirical studies of Carl Stumpf (1873, p. 108), but it was Husserl who gave an ontological dimension to it by turning (in)dependence into an a priori relation between parts and whole. Formally, a dependent part requires, in order to exist, a more embracing whole in which it finds completion. Unlike independent parts, which Husserl calls 'pieces,' dependent parts are 'moments' of their whole, because they are inseparable from it. A whole consisting of dependent parts thus always consists of a surplus that is not included in the mere sum of the moments. In more recent terms, we can say that this surplus consists of the 'holistic properties' of a 
whole that emerges from the parts' (and their 'component properties') interrelations (cf. Wagemans et al., 2012, p. 9). On the contrary, a whole consisting only of pieces is classifiable as an agglomeration, because the pieces can be arbitrarily added to or separated from the whole. Since this is a formal-ontological distinction, it applies to and finds instantiations in the reality of experiences.

Let us take again an apple as an example. Like most objects in a material ontology, an apple is a whole that includes both pieces and moments. On the one hand, we can separate parts of an apple such as its skin, core and seeds (which we theoretically can put together again to have a complete apple). The fact that we can separate such parts means that they are 'discontinuous' in relation to another. Once separated, they can "become wholes in themselves and are no longer parts. Pieces, then, are parts that can become wholes" (Sokolowski, 2000, p. 23). On the other hand, we cannot separate the different colors, the taste, the freshness, the vitamins, the price or the symbolic values from the apple. They cannot exist without their whole and therefore would not become wholes in their own right. Although we can distinguish such moments in our experience, they are continuous ('fused') with each other such that we cannot delimit their space-time position. Whereas pieces thus refer to parts with a physical, singular extension in space and time, which is what John Locke calls the 'primary qualities' of an object, moments denote secondary and tertiary qualities, i.e. immaterial yet experienceable aspects of a physical object, and also a more global situation, an atmosphere, a social setting, a culture, shared values, etc.

A standard way to conceptualize pieces and moments is by placing them in a framework consisting of a horizontal and a vertical dimension. The horizontal dimension is reserved for pieces and their agglomerations, which are nothing beyond the sum of their individual pieces. This is the so-called 'flat ontology,' in which an addition of material parts does not yield or require a whole of a higher order with emergent qualities the parts do not possess. In this sense, a cup of coffee would be nothing else than an agglomeration of its handle, bowl and the liquid inside. These parts are themselves agglomerations of simpler pieces (down to the atomic level), which is why pieces can be wholes in their own right. Their independent way of relating to each other is by coexistence, comparable to the pieces of a puzzle, which entails a continuity of the pieces' existence once the correlation diminishes. Since pieces can be agglomerations in their own right, agglomerations are nothing but pieces for further possible constellations of coexistence.

However, a cup of coffee also consists of parts like colors, flavors, a temperature and a usually inviting 'affordance' (Gibson) of 'you should drink me.' Husserl explains that such moments are 'founded' by the whole in which they appear, because they exist as such and such only via this whole and the completion it provides. In so doing, moments exist in a hierarchical, nonarbitrary pattern in which 
what ranks higher is a founding whole for the 'lower' moments that depend on it. As Sokolowski (2000, p. 24) writes in this regard,

"there can be several layers of founding: shade is founded upon hue, which in turn is founded upon color. In this case, shade is only mediately founded upon color (via hue), while hue is immediately founded upon color. Pitch and timbre, however, are both immediately founded upon sound."

This example from the side of material ontology is derived from the universal validity of formal ontology, i.e. "[ $\mathrm{t}]$ he order of mediacy and immediacy is based by law on the pure Genera involved" (Husserl, 2001, p. 28). The conceptualization of parts on the basis of these two dimensions is widespread up to the present day, with an often uncritical preference for a flat ontology of material parts in contemporary mereology (with the slogan: 'composition [of parts] as identity [in their sum]') and a slightly more critical acceptance of a vertical hierarchy in studies on emergence, including Gestalt-theoretical approaches in this context.

Let us now try to reflect on the possibility that a part does not only depend on a more embracing whole but that this whole also depends on one or more of its parts. This MI is impossible to think through in a purely conceptual manner, thus in a formal-ontological sense. There are at least two reasons why this is the case. First, we would end up with an infinite proliferation of entities. For a whole to depend on its moments, we would need to determine on which parts exactly it depends. This implies that the just described continuity of dependent parts, i.e. their inseparable fusion, would have to be turned into a piece-like distinguishability. In Husserl's own words:

"If then $U$ is the moment of unity of $A$ and $B$, there must be a new 'moment' of unity $U_{1}$, for $A$ and $U$ (since these two are unified) and again a new $U_{2}$, for $\mathrm{B}$ and $\mathrm{U}$; and just so new 'moments' $U_{1}$ and $U_{2}$, for $U$ and $U_{1}$, and for $U$ and $U_{2}$ respectively, and so on in infinitum." (id., p. 37)

In addition to this 'bad infinity' (Hegel) our thinking of MI would result in, there is another reason for MI's formal impossibility: it would violate the abovementioned laws of asymmetry and irreflexibility and therefore lead to (mereo-)logical inconsistencies. This is because in this model, a dependent entity can only exist when it finds completion in something more comprehensive than itself. If this entity would embrace its own completion from the outset, then it would exist independently of other entities. However, for a whole that depends on parts it (partly) consists of, we would need to assume that the parts are more comprehensive than the whole itself in order to provide existential completion for it. Otherwise, the whole would already carry its own completion within itself and would not be dependent in this regard. Thus, a whole's moments would have to function as wholes that are in some sense 'richer' or more embracing than the 
original whole for this whole to exist. Against asymmetry, if moment $m$ is part of whole $w$ and $w$ depends on $m$, then $w$ has to be part of $m$. Against irreflexivity, $w$ then would have to be part of itself, like in a fractal. In a formal-ontological sense, i.e. in the realm of pure thinking, this, together with the infinite regress, seems to be impossible. It would both turn the vertical dimension's hierarchy constantly upside down and make it drift into an endless height.

At the same time, we saw that Husserl's model is versatile enough to state that the realm of pure thinking with its a priori laws is not the only domain in which part-whole relations can be understood. This domain, which is covered by a formal ontology, is supposed to be the conditional benchmark for what a material ontology can determine. It is therefore privileged by the Husserl of the Logical Investigations. However, it is the latter's domain of experience in which the (in)consistencies of pure thinking are not necessarily a decisive factor for particular experience's degree of reality. In the case of what I call MI, Husserl concedes that in some situations, we do not experience primarily the whole (on which parts depend) or primarily the parts (on which a whole depends) such that one side would determine the other. Instead, we have to bidrectionally go through the moments to the whole and from the whole to the moments in a reciprocally mediating manner to arrive at a comprehensive experience of an object or situation. For example, the taste and color of an apple are inseparable from the whole apple, but it is through tasting and seeing that we determine the existence of the apple as, e.g., ripe (the prototype) or rotten (not really 'an apple' anymore). Only in also recognizing the moments as moments in their own right can they mediate the whole that therefore depends on them. Then, we both perceive a whole as whole via its parts (Husserl, 2003, pp. 216-7):

"we pick out the quasi-qualitative Moment [here: the whole] in the manner of something simple, and [...] it nevertheless is subsequently to be analyzed into a multiplicity of parts noticeable in their own right.") and we perceive a part as part via the whole. Between moments and whole, there is a sort of peculiarly intimate mutual interconnection which must at a stroke set the whole complex of interpenetrating moments in relief, if only once a single discontinuous moment has provided the right conditions." (Husserl, 2001, p. 16)

We saw how this continuous, bidirectional process of $\mathrm{MI}$ is formally-ontologically inconsistent and leads to an infinite regress. Therefore, Husserl warns us to not confuse the formal distinction between dependence and independence. In the experiences of such a formally invalid confusion,

"we are dealing with differences of 'subjective', intuitive materials, which have their own remarkable peculiarities of essence, but which will not help us to grasp the universal, ontological difference between abstract and 
concrete contents, or, as we deliberately called them above, independent and non-independent contents." (id., p. 17)

In other words, we have arrived at a situation in which the model points beyond itself, i.e. in which what is modeled as thinkable cannot cope with some of our concrete experiences. In Husserl's (id.) view, "anything that holds water in this descriptive situation is mixed up with other quite alien matters, and is in any case unfitted to illuminate our ontological distinction." The aim is thus to leave his model behind due to its insufficient veridicality and to rethink MI in a consistent way by offering a form of thinking that includes this phenomenon instead of prescribing formal conditions that prevent the chance of any adaequatio rei et intellectus in this regard. Therefore, we have to take a closer look at the actual experienceability of MI and its being 'mixed up with other quite alien matters' to infer from there how to enable its structural thinkability.

\section{Experiencing Mereological Interdependence: B. Pinna}

Owing to its closeness to the subject matter, its philosophical heritage and its interisciplinary nature, Gestalt-psychological research on part-whole perception can teach us more about the experienceability of MI. However, not every approach within this discipline is equally serviceable in this context. In particular, the pioneering and therefore most influential studies seem to privilege a one-sided dependency of either the whole on the parts or the other way round. Christian von Ehrenfels, for example, argues in his seminal 1890 article 'On Gestalt qualities' that a supra-summative, perceptual whole is basically reducible to its (stimulus) parts if only we subtract one additional quality that is added by our cognitive apparatus: the Gestalt quality. He thus adopts a rather (but not fully) atomistic picture of reality, according to which its most fundamental structure is a finite number of indivisible building blocks ('pieces' in the Husserlian sense) aka stimulus parts or "proto-qualities" (Von Ehrenfels, 1988, p. 51). On the other hand, a psychologist-philosopher like Max Wertheimer defends in his writings on visual perception a dependence relation of parts on the perceived whole such that the former are "determined by whole-conditions and the events initiated by their occurrence run a course defined by the laws of functional dependence in wholes" (Wertheimer, 1938, p. 14). It is rather more recent Gestalt-psychological research that tends to hypothesize a two-sided dependence relation between perceived parts and their whole (cf. for example, Hoffman \& Richards, 1984; Lee \& Mumford 2003; van der Helm, 2012). This is in particular the case in research that distinguishes between the bottom-up process of perception, resulting in the primary perception of a whole, and the top-down process of attention or awareness, in which a whole can be subsequently analyzed into its constituent parts (cf. Hochstein \& Ahissar, 2002; Koenderink, 2012; van der Helm, 2017). 
In the context of such approaches and for a philosophical perspective, the research of B. Pinna (partly co-authored with Liliana Albertazzi) is particularly interesting to concentrate on. He considers the notion of perceived (visual) meaning, to which everyone can easily relate, by making use of the descriptive method of (experimental) phenomenology. In doing so, Pinna avoids the problematic Cartesian mind-world dualism, which is often taken for granted even in recent Gestalt theory and which takes for granted a 'critical realism' according to which we can never experience the world as it is, because as subjects, we would only rely on mental representations of it (cf. Bischof, 1966). He also avoids any strict separation between perception and attention, which seems rather artificial and at best gradual in the context of lived, everyday experience. Furthermore, Pinna explicitly reflects on the notion of a part-whole hierarchy in this regard, which is very helpful for the present investigation to rethink this hierarchy in the context of MI. To be precise, instead of a pointed, triangular hierarchy with whole formations toward the top $(\mathbf{\Lambda})$, we can visualize the part-whole hierarchy suggested by Pinna by stacking an additional diamond ( $\downarrow$ on top of this triangle. This implies that there is not only an upward movement of wholification and a downward movement of partition but also further partitions of already existing wholes such that in principle, our perception of objects involves a sequence in which (part-)heterogeneity and (whole-)homogeneity alternate. Although this sequence consists of "arbitrary phenomenal separations of a perceptual result that appears indivisible" (Pinna \& Reeves, 2009, p. 229), its separations constitute nonetheless an innovative take on the experience of MI.

The key passage in which this extended type of vertical hierarchy for perceptual part-whole structures is expressed is the following:

"Phenomenally, there are several steps in the 'perceptual organization' (that is also a 'visual interpretation') of the previous whole object in specific shapes and meanings. The first perceptual step is the 'segregation' of each component from the background [lets call it 'partition, ', or ' $p_{1}$ ', M.S.]. The second one is 'putting together' or grouping the segregated elements in homogeneous wholes on the basis of similarity of shape [wholification $\left.1 / w_{1}\right]$. The third is the complementary 'separation' and the clear distinction of the wholes on the basis of dissimilarity $\left[p_{2}\right]$. Similarities and dissimilarities lead to the fourth and final step, where all the differentiated wholes and each single element are put together again by virtue of another and more global grouping factor that overcomes the dissimilarities of the components: it is some kind of meaning principle that perceptually solves the differences among wholes and elements at a higher level making them appear strongly linked just by virtue of the differences $\left[w_{2}\right]$. In this way similarities and dissimilarities complement and do not exclude each other. This can be the level where the perceptual meanings are established.” (id., pp. 228-9) 
Thus, in comparison with rather traditional Gestalt research on part-whole perception, Pinna adds two more steps further upward in the hierarchy, namely, ' $p_{2}$ ' and ' $w_{2}$.' Without postulating these two further steps, we would just arrive at organized, shaped, homogeneous wholes ('Gestalts' in the classical sense) such that the process of perceiving them would end here. This could, however, not explain the fact that we perceive and be aware of such wholes not only as 'lawful' forms of grouped and shaped parts but first and foremost as meaningful entities. Pinna argues and shows in several empirical experiments that the step of $w_{1}$, which leads from part dissimilarity toward whole similarity via laws of grouping and shaping, cannot account for perceptual meaning. For example, a square $\square$ is a very prägnant visual Gestalt, wholified (i.e. shaped) out of four single lines. Such a perfect square is rarely perceived in reality, and due to its perfection, it lacks any singularity that would make it meaningful for the observer. However, if we only slightly rotate this square such that it is in between a square and a diamond (another 'good' Gestalt), we cannot adequately describe our percept simply as 'square' anymore, but we need more than one word for it, in this case, 'rotated square.' The adjective 'rotated' signifies that something has happened to the square (the noun). The stability and 'goodness' of the latter is disturbed, and in order to conceive the 'square' with its attribute of being 'rotated,' we have to turn to the individual parts in order to investigate what is going on. In the context of the square example, the vertical movement of $p_{2}$ becomes even more urgent when the square is not only rotated, but when

"the square and its sides or angles appear as beveled, broken, crashed, gnawed, deliquescing, deformed, protruding," whereby the "changes and happenings can be seen as depending on or related to specific and 'invisible' but perceptible causes affecting the shape and the material properties of the square. They add visual meanings but do not really change the shape of the square, which is perceived like the amodal invariant shape supporting all those happenings [...]." (Pinna, 2011, p. 387)

Thus, while the original, 'good' whole does not entirely disappear when some of its parts affect it (it is 'amodally complete'), it is via the variance of the parts that the whole undergoes a happening, i.e. that it becomes 'modally incomplete.' Only due to this happening, it receives perceptual meanings beyond its pure form and shape ('why is it beveled, broken, etc.? What is going on here? How can we fix it?').

Without creating an artificial gap between perception and attention, Pinna argues that perceptual meanings are "directly and immediately perceived without any cognitive mediation but as a result of some kind of part-whole organization eliciting perceptual meanings [...]" (Pinna \& Reeves, 2009, p. 247). Of course, 
imperfect squares are very simplified examples. As such, however, they make evident that

"what is segregated becomes the happening, i.e. something different from the main meaning (subject). The happening is discounted but at the same time it becomes part of the subject by qualifying it and explaining in terms of action the reason for the loss of homogeneity, integrity and unity of the subject. In this way the subject can assume, establish or restore its homogeneity that is like a basic assumption within the process of meaning formation." (Pinna, 2010, p. 66)

Thus, whereas the perceptual whole is primary in relation to the parts it groups and shapes, its actual, amodal completeness is only maintained by the parts that makes it - paradoxically-modally incomplete, but in so doing imbues it with perceptual meaning. In other words, whereas $w_{1}$ implies part dependence on the whole and signifies a tendency toward homogeneity, the perceptual step of $p_{2}$ implies the whole's dependence on the heterogeneous parts in order to be meaningful in perception. Pinna's experimental and theoretical elaboration on perceptual meaning thus clearly involves a version of MI, i.e. "the perceptual meanings within an object are reciprocally determined and complemented in a part-whole organization" (Pinna \& Reeves, 2009, p. 249).

It has to be noted, however, that this version of MI still gives a preference to the holistic character of the Gestalt percept by postulating the final perceptual step of $w_{2}$. In this step, which leads to the top of the 'diamond' in the visualized hierarchy, both the whole homogeneity resulting from $w_{2}$ and the part heterogeneity resulting from $p_{2}$ are united into a more embracing whole. In the end, "many elements are reduced to few integrated meanings" (Pinna, 2010, p. 72). As soon as we become aware of the happening by perceiving one or more of the whole's parts as either being dissimilar to the whole, absent or standing apart from it, thus as soon as the discontinuity between whole and parts becomes evident, we attribute a perceptual meaning to the percept to interpret this discontinuity by putting it in a broader, unifying picture.

"Discontinuities, divergences, contrasts, and paradoxes are solved and 'explained' within a whole meaning. The components are restructured in a meaningful manner: The discontinuity becomes the predicate (happening) of the subject (amodal meaning)." (Pinna \& Albertazzi, 2010, p. 336)

On the one hand, this perceptual step of $w_{2}$ implies a certain invariability of the resulting meaning that makes it resistant to changes in the levels of the previous steps. Such an invariability prevents, for example, the possibility of an infinite proliferation of meanings, since not for every possible relation of parts and whole 
a new meaning is created. Perceptual meanings are relatively stable: if we rotate the square just a little bit more, for example, we would still have the same rotated square and not necessarily a new entity called 'a slightly further rotated square.' On the other hand and not in contradiction with its invariability, the extended hierarchy of perceptual MI comprises a degree of variability in that the perceptual step of $w_{2}$ only implies a temporary final stage in which perceptual meaning is created. As soon as the meaningful Gestalt undergoes any significant changes in its parts, or as soon as it is brought into novel connections with additional Gestalts, the unifying whole that had been the result of $w_{2}$ opens up again in order for new meanings to emerge (cf. Pinna, 2010, p. 71).

Despite this variability that makes the perceptual process of meaning attribution potentially continue after $w_{2}$, we can still critically ask if there is not an overemphasis on the resulting whole in this hierarchy of part-whole interdependence. This is because it assumes that the parts, some of which are originally disordered for the happening to take place and for meaning to emerge, are supposed to adjust to the meaningful whole in the process of $w_{2}$.

"As the whole meaning emerges, each component adjusts to it and takes on new perceptual properties derived from and synergistic with that meaning and, vice versa, the whole meaning emerges as a result of what is perceived in every single component." (Pinna \& Reeves, 2009, p. 228)

In so doing, we have to assume that the necessity of unadjusted parts, which is the existence condition for the perceptually meaningful whole, is turned upside down as soon as this final whole comes into existence. In other words, the diversity that is presupposed by the resulting meaning and that distorts the 'good' form of the percept is turned into a more embracing uniformity of homogeneity and heterogeneity at the (temporary) end of the perceptual process. However, despite this caveat, we can safely conclude that in his reflections on perceptual meaning, Pinna offers a valuable empirical as well as phenomenological framework for MI that goes beyond the tendencies of mereological one-sidedness inherent to former approaches of Gestalt theory and challenges at the same time the (according to Husserl: impossible) thinkability of this notion.

\section{Rethinking Mereological Interdependence: E. Rubin}

Now we return from what Husserl calls the experience-based domain of 'material ontology' to the laws of thinking what is possible in and general for this domain, i.e. to 'formal ontology.' What would be an adequate way to rethink the interdependence of parts and whole in the light of its actual occurrence in meaningful Gestalt experiences, understood as Pinna's 'happenings', i.e. alternations of partitions and wholifications (which does not rule out alternative empirical 
findings on dynamic part-whole relations)? On the one hand, we saw that there is a clear perceptual difference between parts and whole, such that it is inadequate to postulate an identity relation like in the case of material pieces, which would result in a flat ontology of a horizontal dimension. On the other hand, we also cannot postulate a classical, pyramide-shaped hierarchy in which wholes rank higher than one-sided determined parts, because we saw that for meaningful Gestalt experience, the processes of partition are (almost?) as important as processes of wholification. This experienced $\mathrm{MI}$, however, cannot be directly taken over into a formal model, because then we would end up with the inconsistencies and infinite regresses the Husserlian model forced us to leave itself behind. One possible solution would be to rethink MI in a more flexible hierarchy, for example in a formalization of Pinna's vertical upward movement of alternating partitions and wholifications, in which also a heterogeneity of parts is logically allowed to rank higher than a homogeneous whole. We could also elaborate on already existing suggestions of how to conceive of part-whole hierarchies in a more dynamic, bidirectional way, such as W. McCulloch's (cf. 1945) 'heterarchy', A. Koestler's 'holarchy' (1970) or Anjum e.a.'s (cf. 2017) recent model of 'causaltransformative emergence and demergence.' In any case, the aim is to develop or rather discover what H. Leisegang (cf. 1951) calls a 'form of thinking' that is adequate to the experience of $\mathrm{MI}$ in the domain of meaningful Gestalts.

My own proposal, which can only be delineated here and which I developed in more detail elsewhere, ${ }^{1}$ is to conceptualize MI with the help of a third dimension: depth. To be precise, I propose to transfer the (originally experiential) phenomenon of backgrounding and foregrounding into the domain of thinking the proper relation between interdependent, reciprocally causative parts-whole structures. As a start, it is not necessary to go beyond the original studies of E. Rubin on figure-ground perception, in particular on how he describes the moment of switching or reversing that can take place between both levels. In the context of multistable phenomena like these, famously exemplified by the faces-vase figure, Rubin argues that the foreground has a higher degree of form, reality and perceptual meaning (cf. Rubin, 1921, p. 36; 45; 74) compared to the ground. This is also the case for nonreversible perceptions (e.g. a pen lying on a table). There is thus no both/and relation between the two sides, i.e no identity, due to different characteristics. However, what is more and what exactly avoids the traditionally postulated hierarchy of a figure as 'ranking higher' than its ground (cf. Koffka, 1922, p. 566-7), reversible figures also do not display a strict either/or relation. In fact, the foreground of a reversible percept always

\footnotetext{
${ }^{1}$ Cf. my yet unpublished $2018 \mathrm{PhD}$ thesis The Ontological Nature of Part-Whole-Oscillations: An Interdisciplinary Determination (written at the Universities of Ferrara and Vienna).
} 
contains its former or potential nature as a background, while we can find traces of its formerly or potentially being foregrounded in what appears as the ground (cf. Rubin, 1921, p. 33). In other words, "it is possible that when a shape, which is experienced as figure, recedes and becomes ground, it may yet keep something of the characteristics of the figure" (Pind, 2014, p. 96) and vice versa. After some time of switching back and forth, Rubin argues, "it may even happen that both areas of the stimulus are simultaneously experienced as figure" (Rubin, 1921, p. 33, own translation). Thus, in the movement of foregrounding and backgrounding displayed by reversible figures, we can find a bidirectional relation between two interdependent sides in which one is contained in the other without contradiction. What is backgrounded still contains an aspect of its having been and potentially being again a foreground and vice versa. In the case of such multistable phenomena's switching back and forth, the 'pulsating' depth dimension allows for a certain vitality of the otherwise linear and static hierarchy entailed in nonreversible figure-ground relations.

Hypothetically, this bidirectional movement of backgrounding and foregrounding can be regarded as a structural basis for interdependent part-whole relations as well. In implementing the dimension of depth into the mental model with which we can think MI in accordance with its experienceability (e.g. as perceptual meaning in Pinna's sense), we can avoid the infinite regress and inconsistencies that a purely vertical hierarchy of parts and whole implies. The possibility that an perceptible entity can present itself alternately as many and as one would then be formally enabled by neither postulating a strict identity relation between (the sum of) parts and their whole, which would only apply to material pieces, nor by conceptualizing parts and whole as excluding each other due to their differences. Like figure and ground in reversible phenomena, also interdependent parts and whole are containing and reciprocally cause each other. If the whole is accentuated, then the parts are backgrounded and as such continuous in the foregrounded whole. If one or more of the parts is accentuated and thus made discontinuous, then the whole does not disappear, but in a way 'scintillates' through the foregrounded parts and is always present due to its retrievability. This means that MI could relate to multistable, more-dimensional patterns of (thinkable as well as experienceable) part-whole interrelations instead of linear vertical hierarchies that we can go up (toward the whole, as e.g. in Gestalt perception) or down (toward the parts, as e.g. in attention). The dynamics of interdependence would then be - in virtue of Occam's razor - guaranteed by the moment of reversal itself instead by an ongoing extension or shift in direction of the hierarchy. The hypothesis of partwhole reversals for MI, which has already gained evidence in cognitive linguistic research on conceptual metonymy (cf. Radden \& Kövecses, 1999; Ruiz de Mendoza, 2000; Brdar-Szabo \& Brdar, 2011), makes such a linear hierarchy and 
the mereological problems that it implies for the domain of thinking questionable. A future interdisciplinary collaboration of Gestalt psychology, (formal) ontology and cognitive linguistics could elaborate on this kind of rethinking $\mathrm{MI}$ in order to avoid an incompatible Cartesian dualism of direct experience on the one side and our mental models of what is (possibly or impossibly) experienceable on the other side.

\section{Summary}

The present article is a partly ontological, partly Gestalt-psychological discussion of the thinkability of structures in which parts and whole are interdependent (MI). In the first section, I show that in the framework of E. Husserl's formal part-whole ontology, the conceptualization of such an interdependence leads to (mereo)logical problems. The second section turns to and affirms the experience of this interplay between parts and whole, exemplified with B. Pinna's recent research on meaningful Gestalt perception. In the final section, I take the experienceability of MI as a justification to suggest a way of rethinking it. This entails an implementation of the process of foregrounding and backgrounding displayed by reversible figures and originally described by E. Rubin. This can avoid both an identity relation between parts and whole and their mutual exclusion as well as hierarchization due to their apparent differences. It would also guarantee the inherent dynamics of interdependence.

Keywords: Experience, Gestalt, Husserl, Interdependence, Meaning, Mereology, Ontology, Part, Pinna Rubin, Whole

\section{Denken, Erfahren und Neu-Denken mereologischer Interdependenz}

\section{Zusammenfassung}

Der vorliegende Artikel stellt eine teils ontologische, teils gestaltpsychologische Erörterung der Denkbarkeit von Strukturen dar, in denen Teile und Ganzes voneinander abhängig sind ('mereologische Interdependenz'). Im ersten Abschnitt zeige ich auf, dass die Konzeptualisierung einer solchen Interdependenz im Rahmen von E. Husserl's formaler Ontologie von Teilen und Ganzen zu (mereo-)logischen Problem führt. Der zweite Abschnitt wendet sich sodann, veranschaulicht durch B. Pinna’s aktueller Forschung zu bedeutungsvoller Gestaltwahrnehmung, der Erfahrbarkeit dieser Wechselwirkung von Teilen und Ganzem zu und bestätigt selbige. Im letzten Abschnitt ziehe ich die Erfahrbarkeit mereologischer Interdependenz als Rechtfertigung für einen Vorschlag heran, dieses Phänomen neu zu bedenken. Dieser Vorschlag besteht in einer Implementierung des Prozesses von 'backgrounding' und 'foregrounding', welcher in Umschlagfiguren zu Tage tritt und ursprünglich von E. Rubin beschrieben wurde. Damit soll sowohl ein Identitätsverhältnis von Teilen und Ganzen als auch deren gegenseitige Ausschließung und Hierarchisierung aufgrund offensichtlicher Differenzen vermieden und die der wechselseitigen Abhängigkeit innewohnende Dynamik garantiert werden.

Schlüsselwörter: Bedeutung, Erfahrung, Ganzes, Gestalt, Husserl, Interdependenz, Mereologie, Ontologie, Pinna, Rubin, Teil 


\section{References}

Albertazzi, L. (2015). A science of qualities. Biological Theory, 10, 188-199.

Anjum, R., \& Mumford, S. (2017) Emergence and Demergence. In: M. Paoletti \& F. Orilia (Eds.) Philosophical and Scientific Perspectives on Downward Causation (pp. 92-109). New York, London: Routledge.

Arnheim, R. (1974). Art and visual perception: A psychology of the creative eye. Berkeley: University of California Press.

Ash, M. G. (1985). Gestalt psychology: Origins in Germany and reception in the United States. In: C. E. Buxton (Ed.), Points of view in the modern history of psychology (pp. 295-344). Orlando e.a.: Academic Press.

Bischof, N. (1966). Erkenntnistheoretische Grundlagenprobleme der Wahrnehmungspsychologie. In: W. Metzger (Ed.) Handbuch der Psychologie. In 12 Bänden. Bd. 1 (pp. 27-78). Göttingen: Verlag für Psychologie.

Brdar-Szabó, R., \& Brdar, M. (2011) What do metonymic chains reveal about the nature of metonymy? In: F. de Mendoza, R. Benczes \& A. Barcelona (Eds.) Defining metonymy in cognitive linguistics: Towards a consensus view (pp. 217-248). Amsterdam, Philadelphia: John Benjamins.

Gabriel, M. (2018). Der Sinn des Denkens. Berlin: Ullstein.

Harrington, A. (1996). Reenchanted science: holism in German culture from Wilhelm 2 to Hitler. Princeton: Princeton University Press.

Hochstein, S., \& Ahissar, M. (2002). View from the top: Hierarchies and reverse hierarchies in the visual system. Neuron, 36, 791-804.

Hoffman, D., Richards, W. (1984). Parts of recognition. Cognition, 18, 65-96.

Husserl, E. (2001). Logical Investigations. London, New York: Routledge.

Husserl, E. (2003). Philosophy of arithmetic: Psychological and logical investigations with supplementary texts from 1887-1901. Dordrecht: Springer.

Koenderink, J. (2012). Visual awareness. Utrecht: De Clootcrans Press.

Koestler, A. (1970). Beyond atomism and holism - the concept of the holon. Perspectives in Biology and Medicine, 13(2), 131-154.

Koffka, K. (1922). Perception: an introduction to the Gestalt-Theory. The Psychological Bulletin, 19(10), 531-585.

Köhler, W. (1939). The place of value in a world of facts. London: Kegan Paul, Trench, Trubner \& Co.

Lee, T. S., \& Mumford, D. (2003). Hierarchical Bayesian inference in the visual cortex. Journal of the Optical Society of America A, 20(7), 1434-1448.

Leisegang, H. (1951). Denkformen. Berlin: W. de Gruyter.

McCulloch, W. (1945). A heterarchy of values determined by the topology of nervous nets. Bulletin of Mathematical Biophysics, 7, 89-93.

Metzger, W. (2001). Psychologie. Die Entwicklung ihrer Grundannahmen seit der Einführung des Experiments. Vienna: Krammer.

Næss, A., \& Haukeland, P. I. (2002). Lifés philosophy: Reason \& feeling in a deeper world. Athens, London: University of Georgia Press.

Pind, Jörgen L. (2014). Edgar rubin and psychology in Denmark: Figure and ground. Dordrecht e.a.: Springer.

Pinna, B. (2010). New Gestalt principles of perceptual organization: An extension from grouping to shape and meaning. Gestalt Theory, 32(1), 11-78.

Pinna, B. (2011). What is the meaning of shape? Gestalt Theory, 33(3/4), 383-422.

Pinna, B., \& Albertazzi, L. (2010). From grouping to visual meanings: A new theory of perceptual organization. In: L. Albertazzi, G. J. van Tonder, \& D. Vishwanath (Eds.) Perception beyond inference: The information content of visual processes (pp. 287-344). Cambridge, London: MIT Press.

Pinna, B., \& Reeves, A. (2009). From perception to art: How vision creates meanings. Spatial Vision, 22(3), $225-272$.

Pomerantz, J. R., Cragin, A. I. (2015). Emergent features and feature combination. In: J. Wagemans (Ed.) The Oxford Handbook of Perceptual Organization (pp. 88-107). Oxford: Oxford University Press.

Radden, G., \& Kövecses, Z. (1999). Towards a theory of metonymy. In: K.-U. Panther, \& G. Radden (Eds.) Metonymy in language and thought (pp. 17-60). Amsterdam, Philadelphia: John Benjamins.

Rausch, E. (1967). Über Summativität und Nichtsummativität. Darmstadt: Wissenschaftliche Buchgesellschaft.

Rubin, E. (1921). Visuell wahrgenommene Figuren. Studien in psychologischer Analyse. Kopenhagen e.a.: Gyldendalske Boghandel.

Ruiz de Mendoza, F. (2000). The role of mappings and domains in understanding metonymy. In: A. Barcelona (Ed.) Metaphor and metonymy at the crossroads: A cognitive perspective (pp. 109-132). Berlin: de Gruyter. 


\section{GESTALT THEORY, Vol. 41, No.1}

Simons, P. M. (1982). The formalisation of Husserl's theory of wholes and parts. In: B. Smith (Ed.) Parts and moments: Studies in logic and formal ontology (pp. 113-159). Munich, Vienna: Philosophia.

Smith, B. (1988). Gestalt theory: An essay in philosophy. Munich, Vienna: Philosophia.

Smith, B. (1994). Austrian philosophy: The Legacy of Franz Brentano. Chicago, LaSalle: Open Court.

Smith, B., \& Mulligan, K. (1982). Pieces of a theory. In: B. Smith (Ed.), Parts and moments: Studies in logic and formal ontology (pp. 15-109). Munich, Vienna: Philosophia.

Smith, B., \& Smith, D. W. (1995). Introduction. In: B. Smith, \& D. W. Smith (Eds.), The Cambridge companion to Husserl (pp. 1-44). Cambridge: Cambridge University Press.

Sokolowski, R. (2000). Introduction to phenomenology. Cambridge: Cambridge University Press.

Ströker, E. (2009). Husserls Logische Untersuchungen. Ein Werk des Durchbruchs zur Phänomenologie. In: E. Husserl, Logische Untersuchungen (pp. xxvii-lxxiii). Hamburg: Felix Meiner.

Stumpf, C. (1873). Über den psychologischen Ursprung der Raumvorstellung. Leipzig: S. Hirzel.

van der Helm, P. (2012). Cognitive architecture of perceptual organization: From neurons to gnosons. Cognitive Processing, 13, 13-40.

van der Helm, P. (2017). Human visual perceptual organization beats thinking on speed. Attention, Perception, \& Psychophysics, 79, 1227-1238.

Varzi, A. C. (2016). Mereology. In: The Stanford Encyclopedia of Philosophy, https://plato.stanford.edu/entries/ mereology/(last visited 1 October 2018).

Von Ehrenfels, C. (1988). On 'gestalt qualities.' In: B. Smith (Ed.), Foundations of Gestalt theory (pp. 82-117). Munich, Vienna: Philosophia.

Wagemans, J., Feldman, J., Gepshtein, S., Kimchi, R., Pomerantz, J., van der Helm, P., van Leeuwen, C. (2012). A century of gestalt psychology in visual perception II. Conceptual and theoretical foundations. Psychological Bulletin, 138(6), 1218-1252.

Wertheimer, M. (1938). The general theoretical situation (Untersuchungen zur Lehre von der Gestalt I). In: W. D. Ellis (Ed.) A source book of gestalt psychology (pp. 12-16). Abingdon: Routledge.

Michael W. Stadler (born in 1986) studied philosophy at the Universities of Nijmegen, Luxemburg, Memphis (TN) and Prague. He wrote his PhD thesis entitled 'The Ontological Nature of Part-Whole-Oscillations: An Interdisciplinary Investigation' (defended in March 2018) at the Universities of Ferrara and Vienna. Currently, Stadler is working on the notion of 'thinking' in problem solving and (the history of) philosophy.

Address: Liechtensteinstraße 65A Top 10, 1090 Vienna, Austria

Email: michi[dot]stadler[at]posteo[dot]de 